\title{
Windows to Cell Function and Dysfunction: Signatures Written in the Boun- dary Layers
}

\author{
Peter J.S. Smith*, Leon P. Collis and Mark A. Messerli \\ BioCurrents Research Center, \\ Cellular Dynamics Program \\ Marine Biological Laboratory \\ Woods Hole MA 02543 USA \\ *psmith@mbl.edu: Corresponding author
}

\begin{abstract}
The medium surrounding cells either in culture or in tissues contains a chemical mix varying with cell state. As solutes move in and out of the cytoplasmic compartment they set up characteristic signatures in the cellular boundary layers. These layers are complex physical and chemical environments whose profiles both reflect cell physiology and provide conduits for intercellular messaging. Here we review some of the most relevant characteristics of the extracellular/intercellular space. Our initial focus is primarily with cultured cells but we extend our consideration to the far more complex environment of tissues and discuss how chemical signatures in the boundary layer can or may affect cell function. Critical to the entire essay are the methods used, or being developed, to monitor chemical profiles in the boundary layers. We review recent developments in ultramicro electrochemical sensors and tailored optical reporters suitable for the task in hand.
\end{abstract}

\section{Introduction}

The advent of electron tomography with 3 dimensional image reconstruction has revealed a fundamental beauty and complexity behind the structure of the living cell. Notable contributions have come from several imaging laboratories but one of the most compelling can be found in Marsh et al. ${ }^{(1)}$ From such reconstructions the complexity within a cell is quite staggering and in the $4^{\text {th }}$ dimension of time this entire structure is in motion. The question that becomes extremely interesting is how molecular and ionic signals are regulated and move within these matrices, where chemical diffusion will be significantly altered. ${ }^{(2)}$ However, complexity, both structural and functional, does not stop at the plasma membrane but extends outwards into the extracellular/intercellular space (EICS: Fig.1). The chemical dynamics within this space are hypothesized to play key roles in cancer, spreading depression, epilepsy and sleep disorders. ${ }^{(3-6)}$ The purpose of this essay is to consider what we can learn from this space and the methods for following the dynamics of chemical movement within the diffusive boundary layers that comprise an integral part of a cell. We will start by noting the physical and chemical features involved.

Chemical signatures within the EICS of tissues have been implicated in several aspects of cell physiology and control. Two cases have been extensively studied, hormonal signaling and the synapse. In a chemical synapse, the gap between the pre and post synaptic structures, the synaptic cleft, is approximately $20 \mathrm{~nm}$ wide. Chemical signals secreted into this cleft are constrained such that the maximum rate of information transfer approximates to the Diffusion Coefficient $(D)$ and the square of the distance $\left(x^{2}\right)$ between the terminals ${ }^{(2)}$ such that:

Information transfer $\approx D / x^{2}$

The word synapse is derived from Sherrington and colleagues' synaptein, combining the Greek syn and haptein, giving us clasping together. However, in non-synaptic areas within tissues, such as the brain, cells frequently lie within tens of nanometers of each other, giving rise to both an integral association and profound tortuosity. ${ }^{(7,8)}$ Elements of the structural boundary layer, the glycocalyx, will overlap in these constrained spaces, blurring the boundaries of one cell to another. When considering cellular physiology, the impact of extracellular functional nanodomains is given short shrift. Chemical changes (cellular signatures) within this space play a role in cell function and we can use them to understand cell state. Let us consider a single cell and roughly define the functional spaces and properties of the extracellular domain. 


\section{Chemical Boundaries, Diffusion and the Unstirred Layer}

Fluid volumes surrounding cells, particularly in culture, form unstirred layers (USL). This is a natural property of water and can extend away from the cell surface by $30 \mu \mathrm{m}$ in fast flowing systems to several hundred microns in still media. ${ }^{(9,10)}$ Even under extreme conditions of mixing, levels which would destroy most cells, this layer remains at approximately $0.7 \mu \mathrm{m} .{ }^{(11)}$ Within the USL diffusion dominates solute transfer and is defined by the Stokes-Einstein (Sutherland-Einstein) equation such that:

$D=R T / 6 \pi r \eta \AA ̊ ́$

where, $D$ is the Diffusion Coefficient, a measure of the molecular mobility, $R$ is the gas constant, $T$ is absolute temperature, $r$ is the radius of gyration or Brownian motion (driven by thermal vibration), $\eta$ is solvent viscosity and $A$ is Avogado's number. Molecules diffusing through the USL to the plasma membrane may then partition into the lipid bilayer. Whereas Overton's Rule would dictate that the partition coefficient into the membrane is the primary determinant of the permeation coefficient recent work brings this long standing rule into doubt. ${ }^{(11)}$ The USL itself will impact significantly depending upon the solute ${ }^{(11)}$. Where the membrane forms an impermeable layer, the activity in the USL approximates that of the bulk solution. When the membrane is permeable, as with oxygen and carbon dioxide, the USL can be the principle barrier to chemical transfer between the bulk and the inside of the cell, thus breaking Overton's Rule. Equally, however, when the membrane exhibits a regulated permeability to an ion or molecule, diffusive boundary layers can be established in the immediate proximity of the membrane within the USL. Under these circumstances a diffusional flux, $J$, will be established according to Fick's $1^{\text {st }}$ law of diffusion such that:

$J=-D \nabla \Phi$

Where, $\nabla$ is the gradient operator for diffusion in two or more dimensions, $\Phi$ is the concentration in dimensions of mols, and $D$ is the diffusion coefficient.

When studying cells in culture, the diffusion coefficient closely approximates to that in an aqueous medium. But, as with the cytosol $^{(2)}$, random motion in the EICS in tissues will deviate from simple diffusion. As diffusion is inversely proportional to the medium viscosity, relates to tortuosity, binding events and the volume fraction $^{(12,13)}$ we need to consider the effective or apparent diffusion coefficient $\left(D_{\text {eff }}\right)$. Permeability through the EICS $\left(P_{e}\right)$ will be:

$P_{e}=D_{\text {eff }} \mathrm{X}$

As we approach a cell membrane, where gaseous profiles reflect active consumption or production and molecular or ionic profiles are modified by membrane transport and boundary conditions, the USL takes on a heterogeneity reflecting cellular activity. As we get closer to the membrane the physical chemistry gets progressively more complicated.

Nanometers from the membrane, such as within the membrane glycocalyx, new physical properties impact the chemical activity. Stock and Schwab ${ }^{(14)}$ refer to this as a "shielded space" where molecular interactions can be fine tuned. For example, the presence of a membrane generates localized electric fields at the interface with the bulk medium. While Fick's law describes the particle movement, both charged and uncharged, along a concentration gradient, it does not account for the effect of an electric field on charged solutes. Diffusion is a statistical probability of movement by Brownian motion. ${ }^{(15)}$ In contrast, electric fields can induce a direct force on particles, termed electrodiffusion. This phenomenon is expressed as the Nernst-Planck equation ${ }^{(16)}$ a combination of Fick's Law and Kohlrausch's Law ${ }^{(17,18)}$ defining the diffusional and electrophoretic influences on ions respectively. Membrane bound negatively-charged phospholipids and glycoproteins create a compact layer of counter ions separated by water molecules. ${ }^{(19,20)}$ This diffuse double-layer, known as the Gouy-Chapman Layer ${ }^{(19,21)}$ exhibits a field strength that dissipates rapidly, nanometers from the membrane. Accounting for the structural heterogeneity of the lipid bilayer and thermal motion of molecules leads to a model with a smearing of charge that is perpendicular to the membrane surface ${ }^{(22)}$ which can in turn affect cell physiology. For instance, cation channel conductance increases in negatively charged membranes due to the accumulation of cations within the Gouy-Chapman Layer. ${ }^{(23)}$ Elec- 
tric fields can project further and exist in the bulk volume of the EICS where they may influence transport kinetics of solutes and neighboring cells. ${ }^{(24,25)}$

Within the boundary layers associated with the glycocalyx the structure of water itself can affect the movement of ions. The latter is termed the Grotthuss mechanism, which explains the unexpectedly high diffusion rate for protons relative to similar cations governed by simple molecular diffusion, i.e. proton diffusion is uncoupled from the self-diffusion of its mass. ${ }^{(26)}$ In dilute buffer this proton migration can occur along the membrane surface over distances around $100 \mu \mathrm{m}$. In physiological buffer the range is smaller, being reduced to approximately $10 \mathrm{~nm}^{(26)}$ but with pump densities of thousands per square micron ${ }^{(16,27)}$ there may still be a tangible physiological effect.

Properties of biological membrane surfaces are difficult to measure directly and so their action on cell physiology frequently remains controversial. However, while it is clear that cell activity gives rise to distinct chemical signatures, the measurement of such signatures has remained a challenge. This challenge can be addressed using electrochemical sensors of micron dimensions. At the heart of this effort lies the application of electrochemical microelectrodes (ECMs: outer diameter $<5 \mu \mathrm{m}$ ) operating in a modulation mode termed 'self-referencing' ${ }^{(28,29)}$ and first described by Kühtreiber and Jaffe. ${ }^{(30)}$

\section{Measuring Chemical Signatures In Vitro}

20 In the self-referencing system, an ECM is automatically translated between two poles, one near the cell or tissue surface, the other further away (Fig. 2). This technique has been largely developed at the BioCurrents Research Center, sponsored by the NIH:NCRR at the MBL, Woods Hole. In application the distance of translation varies but for single cells is set by default at $10 \mu \mathrm{m}$ with the near pole position being approximately $3-5 \mu \mathrm{m}$ from the cell surface. Parameters can be set independently depending on the circumstance. Both poles should be within the diffusion gradient set up by the influx or efflux of the analyte. Data are collected at 1000 values per second with filtering for movement artifacts and stabilization after translation. The motion approximates a square wave with averaging and subsequent processing comparing the voltage or current (potentiometric or amperometric) measured at the two poles during a stationary period of approximately one second.

Flow resulting from the motion of the ECM can be assessed by calculating the Reynolds Number. An approximate Reynolds Number $(\mathrm{Re})$ for the default system is $1.61 \cdot 10^{-4}$ (ECM tip diameter of $4 \mu \mathrm{m}(\mathrm{L}$ in $\mathrm{m})$ moving at a translational velocity ( $\mathrm{V}$ in $\mathrm{m} / \mathrm{s})$ of $40 \mu \mathrm{m} / \mathrm{s})$. As calculated by:

$\operatorname{Re}=\rho \mathrm{VL} / \mu$

Where $\rho$ is the density of the medium $\left(175 \mathrm{mM} \mathrm{NaCl}\right.$ is $1005.3 \mathrm{~kg} / \mathrm{m}^{3}$ and $\mu$ is the dynamic viscosity of the medium (Pa.s: $175 \mathrm{mM} \mathrm{NaCl}$ is $1.02 \mathrm{mPa} \cdot \mathrm{s}$ ). Even $1 \mathrm{~mm}$ further up the electrode shaft, where the pipette diameter is approximately $150 \mu \mathrm{m}$, the Re will be $6 \cdot 10^{-3}$. These values are well below a range of 0.1 to 1 , so flow due to ECM movement falls into a subcategory of laminar flow referred to as creeping flow or Stokes flow. Stokes flow is instantaneous, such that no flow continues after movement.

How long might it take for a concentration gradient to be re-established if it has been disturbed? Analytes measured by the self referencing technique have diffusion coefficients ranging from $9.3 \cdot 10^{-5} \mathrm{~cm}^{2} / \mathrm{s}\left(\mathrm{H}^{+}\right)$to $6.7 \cdot 10^{-6} \mathrm{~cm}^{2} / \mathrm{s}$ (glucose). They will diffuse over a distance of $10 \mu \mathrm{m}$ in about $2-25 \mathrm{~ms}$. A wait time of $0.25 \mathrm{~s}$ at the new pole of excursion prior to data collection allows this process to occur many times over for sensors with a radius of about $2 \mu \mathrm{m}$. Other artifacts are possible, for example, where the analyte is being consumed or the electrode acts as a 'trap' (see below).

50 Comparing the output values from the ECMs at the two pole of measurement gives us a differential value, which can be converted to a flux using Fick's $1^{\text {st }}$ equation with knowledge of the background concentration, distance of translation, the diffusion coefficient and calibration. For potentiometric and amperometric sensors this approach enhances detection by approximately 1000 -fold over data derived from stationary electrodes. Key to this sensitivity increase is minimizing the impact of drift on the signal and the subtraction of analyte background signals as well as non-selectivities. These factors inevitably compromise the perfor- 
mance of the sensors, particularly potentiometric designs where a Nernstian behavior makes the response to interference complex, as described by a modified Nicolsky-Eisenman equation. ${ }^{(31)}$ It should be noted that by referencing the electrode to itself, at both positions, many of the factors which compromise sensitivity become common to both poles of translation and, therefore, subtract out when the differential is calculated. The technique measures a net flux within the domain being measured. With this approach, flux values from single cells, changing over tens of seconds, can be followed in near to real time, with square micron spatial resolution.

The self-referencing technique has proven a versatile and robust approach to quantifying the chemical signatures within the diffusive boundary layers surrounding single cells. Published applications have ranged from work on single cells, to epithelial structures, to select organisms. Biomedical subjects range from disease states, such as diabetes and reproductive infertility, to development and properties of excitable cells and excitotoxicity. Diverse sensor designs have been brought into play with a continued strength being found in the potentiometric ion selective microelectrodes but with increasing interest in the amperometric, solid state electrodes. ${ }^{(28,29)}$ Potentiometric applications have taken advantage of the several excellent ionselective cocktails available commercially, notably for hydrogen, potassium and calcium, with modified cocktails being developed specifically for self-referencing detection of chloride or sodium ${ }^{(32)}$ and rapid response time potassium sensors. ${ }^{(33,34)}$ Amperometric detection depends on reduction/oxidation chemistry. Detection of nitric oxide, oxygen and hydrogen peroxide are now routine applications (sensor fabrication $\left.^{(29,35)}\right)$. Oxygen detection from single neurons plus imaging to identify expression of inserted and labeled genes is proving a unique and powerful application of the technology ${ }^{(36)}$ with electrochemical detection limits being superior to other approaches, even in a non-self-referencing, single point mode. ${ }^{(37,38)}$

The micron dimensions of ECMs allow for specific targeting of regions on a single cell; regions dense in mitochondria (Fig. 3). Additionally, with both potentiometric and amperometric sensors, a particular cell type or expressing cell can be selected from a heterogeneous population. In Fig.3, hippocampal neurons were transfected with adenovirus carrying a construct for GFP and BCL-xL, an anti-apoptotic protein with effects on mitochondrial proliferation and synapse formation. ${ }^{(39)}$ Neurons expressing the construct can be selected from a heterogeneous population of non-transfected neurons, glia and fibroblasts. Oxygen flux data from these preparations show a measurable suppression of transfected neuronal oxygen consumption (L. Collis et al, in preparation).

As data from self-referencing ECMs are collected when the sensor is stationary for approximately 1 second, and data are processed, the technique is slow. It follows activity changes over 10s of seconds, minutes or even hours. This characterizes slow events, or long term changes with pharmacological or gene manipulation. It has proven a powerful methodology for studying pumps and exchangers and the net activity of channels. ${ }^{(28,29,40)}$ It does not, however, discriminate rapid events.

A list of identified native and expressed plasma membrane ion channels, transporters and exchangers characterized by monitoring extracellular ion gradients with ion-selective microelectrodes (ISMs) is shown in Table 1. Of note are the characterization of the regulation of plasma membrane $\mathrm{V}$-type $\mathrm{H}^{+}$transporters, the non-invasive identification of the two-pore $\mathrm{K}^{+}$channel during apoptosis in mouse oocytes, and the characterization of the stoichiometry of the $\mathrm{Na}^{+} / \mathrm{Ca}^{2+}$ exchanger from isolated membrane patches in cardiac myocytes. In this final example new insights into the stoichiometry of the $\mathrm{Na}^{+} / \mathrm{Ca}^{2+}$ exchanger relied on the simultaneous measurement of transmembrane current with voltage clamp and measurement of $\mathrm{Na}^{+}$and $\mathrm{Ca}^{2+}$ gradients with ISMs. Kang and Hilgemann ${ }^{(41)}$ determined multiple stoichiometric states for this exchanger. Without the sensitivity and versatility of electrochemical detection these experiments would not have been possible.

\section{Single Channels Detected in the USL}

It has been assumed that the response of an ISM is relatively slow. However, response times reported by others $^{(42-45)}$ as well as our own recent experience, show clearly that a $90 \%$ response can be achieved in the millisecond range, opening up new possibilities for signal extraction. Can single ion channel events be captured by their signatures? The data presented in Fig. 4 answers this question and illustrates the recording of single potassium channels. ${ }^{(33,34)}$ Using the $\mathrm{CHO}$ heterologous system we also demonstrated that the microelectrode acts as an ion-trap, amplifying the signal from the channel. Obtaining a rapid response potas- 
sium electrode did require design changes in both the electrode body and the ionophore cocktail. Studies on primary hippocampal neurons have demonstrated that this technique can measure native potassium channels coinciding with endogenous calcium ion activity (P.J.S. Smith and L. Collis, unpublished). This has broad implications as current methodologies involving patch, voltage, or current, clamp are inherently invasive. Several aspects of channel dynamics are affected by the experiment and the physical immobilization of a patch within the electrode. For instance the activity of numerous channels, such as the BK channel $^{(46)}, \mathrm{K}_{\text {ATP }}$ channels ${ }^{(47)}$ and stretch-activated channels ${ }^{(48)}$ are regulated by alterations in actin dynamics and cytoskeletal reorganization, a regulation which must be impacted by membrane immobilization. In cardiac myocytes the lack of functional coupling between $\mathrm{Ca}^{2+}$ channels and intracellular $\mathrm{Ca}^{2+}$ release has been attributed to giga-seal formation. ${ }^{(49)}$ The regulation of $\mathrm{Ca}^{2+}$ channels by protein kinases is abolished after forming a tight cell-attached seal on a channel. ${ }^{(50)}$ Thus, noninvasive ISMs may currently represent the only method to monitor channel activity under physiological conditions and stimulation, with no perturbation of the membrane and cytoplasmic environment.

\section{Impact of Chemical Profiles in vivo}

In tissues the unstirred layer and diffusive boundary layer will normally be highly restricted. (Although tubular structures, such as vessels and ducts, can be wide enough to exhibit an USL). The chemical synapse, introduced at the beginning of this essay, is a beautiful example of how efficient information transfer can be aided by a tight spatial organization. As mentioned, although the synapse is an extreme example, cells are frequently in close proximity to each other, often within tens to hundreds of nanometers. This leads to small volumes between cells, volumes where diverse chemical processing could occur. This gives rise to the concept of extrasynaptic or non-synaptic transmission, also known as volume transmission (VT). Although widely accepted, Syková and Nicholson ${ }^{(7)}$ point out that VT "remains an elusive concept that on occasion has prompted fanciful hypotheses about intercellular communication in the CNS". However, within the context of this essay, covering the numerous small molecule 'messengers' that operate in this space and that frequently come with their own specific extracellular receptor is beyond our scope.

Constrained space can be considered to act on cells by concentrating the levels of chemicals, restricting their movement in space, and enhancing their potential impact in time. A good example of this is the potassium ion. Earlier we demonstrated how ISMs can easily detect potassium diffusion profiles from single channel events in both transfected $\mathrm{CHO}$ cells and native hippocampal neurons. Normally these ion fluxes will be constrained by the EICS and exhibit additive properties from sequential or parallel events. As a key component of establishing the membrane potential, and a counter ion to sodium during the action potential, its accumulation outside a neuron will have profound effects on the membrane potential and cell behavior. $^{(51,52)}$. Extracellular accumulation of potassium ions resolves the discrepancy between the membrane excitability of the squid giant axon and the original Hodgkin and Huxley model. ${ }^{(53,54)} \mathrm{An}$ increase in $\left[\mathrm{K}^{+}\right]_{\mathrm{o}}$ can be dealt with by spatial buffering ${ }^{55}$ or potassium reuptake ${ }^{56}$ with potassium activity ranging between $2-12$ $\mathrm{mM}$ for spinal cord and somatosensory cortex ${ }^{(56)}$ with higher levels, in the region of $60 \mathrm{mM}$, being reported for spreading depression. ${ }^{(5)}$ Whereas potassium is clearly important physiologically, the principles of accumulation and sequestration will be generally applicable to other ions and molecules. For instance, local depletion zones of $\mathrm{Ca}^{2+}$ are reported during neuronal activity in the EICS of synapses, leading to subsequent depression of synaptic release. ${ }^{(57)}$ However, following these dynamic changes in tissues is not a trivial problem.

\section{Measuring in vivo profiles}

In vivo electrochemical detection of cellular and chemical activity is an important field with numerous topical applications. ${ }^{(58)}$ A significant problem from the perspective of this essay is placing the sensor within nanovolumes of the EICS, in a manner that does not perturb the very space you are trying to observe. Once a sensor is implanted it is hard to recalibrate, accurately assess fouling or, importantly, assess tissue damage and response. ${ }^{(58)}$ An example of this can be seen when comparing microdialysis results against those derived for the same molecules using $10 \mu \mathrm{m}$ carbon fiber electrochemistry. The results indicate confusion from tissue damage. ${ }^{(59,60)}$ How can we measure in spaces of nanometer dimensions without destroying the very architecture that determines the problem of interest? Below we present two approaches, both with strengths and weaknesses. Each represents an integrated approach to resolving key biological problems. The first approach uses the expression of tailored reporting molecules selectively transported to the plasma membrane. Two examples are given, one measures $\mathrm{pH}$ using ratiometric fluorescence, while the other 
measures ATP levels using luminescent-based imaging technologies. The second approach uses functionalized fine- and nano-particles. We would like to conclude by considering select examples of relatively common molecules that act within the EICS to modify cell performance.

\section{pH in vivo}

Extracellular acidification plays a key role in many aspects of cell biology. In tumors hydrogen ion activity can be abnormally high. ${ }^{(61)}$ In medulloblastoma tissue extracellular acidification activates phospholipase $C$, $\mathrm{IP}_{3}$ formation, and a subsequent intracellular release of calcium. ${ }^{(62)}$ Proton-activated $\mathrm{G}$ protein coupled receptors are involved. Such signaling is proposed to contribute to the action of acidification on neoplastic transformation and tumor aggressiveness, where acidification is brought about by key transporters, such as the Vacuolar $(\mathrm{H}+)$-ATPase. ${ }^{(63)}$ A localized cell surface $\mathrm{pH}$ gradient has also been implicated in cancer cell migration. ${ }^{(3,64,65)}$ Cell migration can be linked to acidification through cancer cell tolerance, initiation of matrix breakdown and neighboring cell death ${ }^{(65)}$. In the brain electrical activity can elicit $\mathrm{pH}$ changes, taking place in milliseconds to minutes. ${ }^{(66,67)}$ Perturbation of the extracellular $\mathrm{pH}$ has been implicated in seizures and spreading depression. Regulation of extracellular $\mathrm{pH}$ involves both buffering and trans-membrane transport. Examples of hydrogen linked transport include the family of $\mathrm{Na}^{+} / \mathrm{H}^{+}$exchangers and counter ion transport by the plasma membrane $\mathrm{Ca}^{2+}$ ATPase. ${ }^{(68)}$ Respiring cells generate $\mathrm{CO}_{2}$ that reacts with water producing bicarbonate and hydrogen ions. Intracellularly this process is governed in part by various carbonic anhydrases (CA). Interestingly, extracellular carbonic anhydrases have been reported for several cell types, with, for example CA IV, XIV and XV being found in the CNS. ${ }^{(69,70)}$

A number of optical methods have already been explored to pursue the idea of placing sensors between cells with minimal damage. These can include the use of freely diffusible fluorescent reporters with $\mathrm{pH}$ sensitivity, such as fluorescein. ${ }^{(71)}$ More powerfully, from our perspective, is the transfection and expression of $\mathrm{pH}$ sensitive molecules, such as $\mathrm{pHluorin}^{(72)}$ on the surface of cells. Expressing cells can then be aggregated into pseudo-tissues or 'tumor' masses, the former exploiting advances in the field of tissue engineering where dielectrophoretic methods are used to control cell position generating controlled aggregations. ${ }^{(73,74)}$ Such tumors could be implanted into xenograft mouse models for the in vivo characterization of $\mathrm{pH}$.

Using a plasmid DNA encoding the ratiometric pHluorin (pGM1) we incorporated GPI anchoring signal sequences from a plasmid construct (pEYFP-GPI). The constructs were provided by Miesenbock (Oxford) and by Edidin (Johns Hopkins). When expressed this causes the pHluorin to be membrane-bound on the outside surface of the cells and to display a good linearity in its $\mathrm{pH}$ response over a workable range. The $\mathrm{pH}$-sensitivity and overall effectiveness of the pHluorin plasmid construct is being tested in the context of a human cancer cell line. The plasmid is now stably expressed in an immortalized human Schwannoma cell line which forms natural clusters in culture, mimicking the in vivo EICS (Fig. 5: Shanta Messerli and David Graham, unpublished). An alternative approach for free cells is to incubate in functionalized wheat germ

40 agglutinin and DHPE, labeling the glycocalyx and plasma membrane respectively, monitoring $\mathrm{pH}$ changes in two compartments of the extracellular domain. ${ }^{(75)}$

\section{ATP in vivo}

For the examples given above we are using fluorescence approaches where the emission intensities are determined by the $\mathrm{pH}$. For ATP measurements we can use a luminescent approach where photon density reflects the chemical activity.

ATP release into the EICS plays a role in cell signaling, particularly in the interactions between neurons and glia. ${ }^{(76-79)}$ Conversion of the ATP to adenosine by ectoenzyme activity and subsequent binding to the neuronal adenosine receptor has been shown. ${ }^{(77)}$ ATP and related nucleotides may act as both fast transmitters via $\mathrm{P} 2 \mathrm{X}$ receptors and as a neuromodulators via $\mathrm{P} 2 \mathrm{Y}$ receptors ${ }^{(80,81)}$, thus modifying the strength of synaptic transmission. In astrocytes direct observation of calcium independent ATP signaling in the EICS has been demonstrated. ${ }^{(82)}$

To measure ATP in the EICS one can use an expressible indicator (GPI-luciferase). The construct contains GPI-linked firefly luciferase, termed pme-LUC (plasma membrane luciferase). ${ }^{(4)}$ A previous method in- 
volved the localization of a reporter to the outside surface via an affinity process, in this case using a protein A-luciferase chimera and coating the cell surface with $\operatorname{lgG} .^{(83)}$ In both cases the addition of luciferin to the medium, in the presence of ATP, causes photon emission. Pellegatti's and colleagues' approach ${ }^{(4)}$ is particularly attractive to the analysis of ATP dynamics in cell aggregates, although they discuss some limitations in the use of the expressible indicator, notably a low affinity allowing measurements only above 5$10 \mu \mathrm{M}$. Their more recent studies on in vivo tumor imaging reveals extracellular levels of ATP in the 100s of $\mu \mathrm{M}$ range. In tumor free tissues the level is undetectable. This significant result indicates a role for ATP not only in growth but also in immunosupression via conversion to adenosine. ${ }^{(4)}$ The above studies will benefit from the generation of transgenic mouse models exhibiting tissue-specific expression of extracellular ATP sensors.

\section{Non-protein based detection}

One drawback of the protein based reporters expressed on the outer surface of cells is the limited number of targetable analytes. Functionalized fine- and nano-particles in conjunction with dielectrophoresis offer a particularly attractive intermediate solution. In this design the reporting particle is not inserted amongst the cells but the cells are assembled around the sensor. ${ }^{(74)}$ Functionalized particles and quantum dots are being studied but have not as yet been applied significantly to the monitoring of analytes within the space surrounding cells. Quantum dots have been used to map both tissues in vivo ${ }^{\left({ }^{84}\right)}$ and the dimensions of the EICS in brain. ${ }^{(8)}$ Notable functional intracellular studies have been undertaken by using "Pebbles" of nano proportions (Photonic Explorers for Bioanalysis with Biologically Localized Embedding). ${ }^{(85)}$ With fine and nano particle chemistry advancing daily, this approach promises a spectrum of sensors covering a wide array of analytes. Perhaps by adjusting the fluorescent characteristics we can acquire multiple boundary layer signatures simultaneously.

\section{Conclusion}

The spaces surrounding cells contain volumes of information written as chemical signatures. Such signatures characterize cell activity reflected by ion transport, diffusion of signaling molecules and gas permeabilities. They provide an insight into the normal and pathophysiological state and play an active role in determining the characteristics of the cell itself. Clear examples of extracellular modulators can be seen in potassium and hydrogen ion activity, as well as ATP and adenosine, a product of ectoenzyme activity. In cultured cells the application of electrochemical microelectrode sensors, operating in a self-referencing mode, can couple to diffusive events within the chemical boundary layer. The technique delivers exquisite sensitivity, reading chemical signals microns from the plasma membrane of a single cell. Examples are discussed from several cell and tissue types, notably from the metabolic characterization of single neurons and hydrogen transport across the mammalian vas deferens. Single, identified, cells can be studied in heterogeneous cultures and transfected cells can be targeted individually for experimentation. Recent advances in tailoring ISMs to enhance the stability and speed of response has allowed non-contact single potassium channel detection from expression systems and primary hippocampal neurons. In tissues, however, cells normally exist in close proximity, separated by nanometers of EICS. Making measurements within these volumes is challenging. New methods using the expression of reporter proteins, such as pHluorin and luciferase, as well as functionalized fine and nano particles, offer promising approaches to documenting the chemical changes taking place in the complex architecture of tissues. With the increasing documentation of ectoenzymic processes, coupled to dynamic chemical and structural changes occurring in the minute volumes of the EICS, this domain deserves an increased prominence in our consideration of cell function and disease.

\section{Acknowledgements}

The development and the application of self-referencing electrodes were funded largely by grant number NIH:NCRR P41 RR001395 to the BioCurrents Research Center (PJSS). The authors would like to thank the long term support of the NCRR and, in particular, Program Officer Abraham Levy. 


\section{References}

1. Marsh BJ, Mastronarde DN, Buttle KF, Howell KE, Mclntosh JR. 2001. Organellar relationships in the Golgi region of the pancreatic beta cell line, HIT-T15, visualized by high resolution electron tomography. Proc Natl Acad Sci U S A. 98(5):2399-406.

2. Weisiger RA. 1998 Impact of extracellular and intracellular diffusion on hepatic uptake kinetics. In: Whole Organ Approaches to Cellular Metabolism. Springer New York. Chapter 16 p389-423.

3. Stüwe L, Müller M, Fabian A, Waning J, Mally S, Noël J, Schwab A, Stock C. 2007. pH dependence of melanoma cell migration: protons extruded by NHE1 dominate protons of the bulk solution. J Physiol. 585(Pt 2):351-60.

4. Pellegatti P, Raffaghello L, Bianchi G, Piccardi F, Pistoia V, Di Virgilio F. 2008. Increased level of extracellular ATP at tumor sites: in vivo imaging with plasma membrane luciferase. PLoS ONE. 3(7):e2599.

5. Somjen GG. 2002. Ion regulation in the brain: implications for pathophysiology. Neuroscientist. 8(3):254-67.

6. Halassa MM, Florian C, Fellin T, Munoz JR, Lee SY, Abel T, Haydon PG, Frank MG. 2009 Astrocytic modulation of sleep homeostasis and cognitive consequences of sleep loss. Neuron. 61(2):213-9.

7. Syková E, Nicholson C. 2008. Diffusion in brain EICS. Physiol Rev. 88(4):1277-340.

8. Thorne RG, Nicholson C. 2006. In vivo diffusion analysis with quantum dots and dextrans predicts the width of brain EICS. Proc Natl Acad Sci USA 103, 5567-5572.

9. Barry PH, Diamond JM. 1984. Effects of unstirred layers on membrane phenomena. Physiol Rev. Jul;64(3):763-872.

10. Mill, PJ. 1997. Invertebrate respiratory systems. Handbook of Physiology, Section 13, Volume 2: 1009-1096.

11. Grime JM, Edwards MA, Rudd NC, Unwin PR. 2008. Quantitative visualization of passive transport across bilayer lipid membranes Proc Natl Acad Sci USA. 105(38):14277-82.

12. Rusakov DA, and Kullmann DM. (1998) Geometric and viscous components of the tortuosity of the EICS in the brain. Proc Natl Acad Sci USA 95:8975-8980

13. Gevertz JL, Torquato S. 2008. A novel three-phase model of brain tissue microstructure. PLoS Computational Biology 4(8): e1000152.

14. Stock C, Schwab A. 2009. Protons make tumor cells move like clockwork. Pflugers Arch. 458(5):981-92.

15. Brown R. 1828. A brief account of microscopical observations made in the months of June, July and August, 1827, on the particles contained in the pollen of plants; and on the general existence of active molecules in organic and inorganic bodies. Philosophical Journal 161.

16. Hille B. 2001. Ion Channels of Excitable Membranes, 3rd ed. Sinauer Associates, Inc., Sunderland, MA.

17. Fick A. 1855. On Liquid Diffusion. Philos. Mag. 10, 30-39.

18. Kohlrausch F. 1899. On the Conductivity of Electrolytes Dissolved in Water in Relation to the Migration of their Components. In The Fundamental Laws of Electrolytic Conduction, ed. Goodwin HM, pp. 83-96. Harper \& Brothers Publishers, New York \& London.

19. Chapman DL. 1913. A Contribution to the Theory of Electrocapillarity. Philos. Mag. 25, 475-481.

20. Forrester JV, Lois N, Zhao M, McCaig C. 2007. The spark of life: the role of electric fields in regulating cell behaviour using the eye as a model system. Ophthalmic Res 39, 4-16.

21. Gouy G. 1910. Constitution of the Electric Charge at the Surface of an Electrolyte. J Phys 9, 457468.

22. Cevc G, Svetina S, \& Zeks B. 1981. Electrostatic potential of bilayer lipid membranes with the structural surface charge smeared perpendicular to the membrane-solution interface. An extension of the Gouy-Chapman diffuse double layer theory. J Phys Chem 85, 1762-1767

50 23. Rostovtseva TK, Aguilella VM, Vodyanoy I, Bezrukov SM, Parsegian VA. 1998. Membrane surfacecharge titration probed by gramicidin A channel conductance. Biophys J 75, 1783-1792

24. Robinson KR, Messerli MA. 2003 Left/right, up/down: the role of endogenous electrical fields as directional signals in development, repair and invasion. Bioessays 25: 759-766.

25. McCaig CD, Zhao M. 1997 Physiological electrical fields modify cell behaviour. Bioessays 19: 819826. 
26. Serowy S, Saparov SM, Antonenko YN, Kozlovsky W, Hagen V, Pohl P. 2003 Structural proton diffusion along lipid bilayers. Biophys J. 84(2 Pt 1):1031-7.

27. Widdicombe, JH, Basbaum CB, Highland E. 1985. Sodium-pump density of cells from dog tracheal mucosa. AJP - Cell Physiology 248, Issue 5 389-C398.

28. Messerli MA, Robinson KR, Smith PJS. 2006. Electrochemical sensor applications to the study of molecular physiology and analyte flux in plants. In: Plant electrophysiology - Theory and Methods. Ed. Alexander G. Volkov. Springer Sections 4.1-4.5.

29. Smith PJS, Sanger RS, Messerli MA. 2007. Principles, development and applications of selfreferencing electrochemical microelectrodes to the determination of fluxes at cell membranes. In: Methods and New Frontiers in Neuroscience. Ed. Adrian C. Michael. CRC Press. Ch. 18: 373-405.

30. Kühtreiber WM, Jaffe LF. 1990 Detection of extracellular calcium gradients with a calcium specific vibrating electrode. J. Cell Biol. 110: 1565-1573.

31. Bakker E, Bühlmann P, Pretsch E. 200). The phase-boundary potential model. Talanta 63, 3-20.

32. Messerli MA, Kurtz I, Smith PJS. 2008. Characterization of Optimized Na+ and Cl- liquid membranes for use with extracellular, self-referencing microelectrodes. Anal. Bioanal. Chem. 390(5): 1355-9.

33. Messerli MA, Corson ED, Smith PJS. 2007. Measuring extracellular ion gradients from single channels with ion-selective microelectrodes. Biophysical Journal. 92(7):L52-4.

34. Messerli MA, Collis LP, Smith PJS. 2009. Ion trapping with fast response, ion-selective microelectrodes enhances detection of extracellular ion channel gradients . Biophys. J. 96(4):1597-605.

35. Oesterle, AL. 2008. Ion Selective and Amperometric Microelectrodes. P-97 Pipette Cookbook (pdf). Sutter Instruments. Chapter 12: 57-58.

36. Gleichmann M, Collis L, Smith PJS, Mattson M. 2009. Simultaneous Single Neuron Recording of O2 Consumption, [Ca2+]i and Mitochondrial Membrane Potential in Glutamate Toxicity. J. of Neurochemistry. 109:644-655.

37. Jung SK, Kauri LM, Qian WJ, Kennedy RT. 2000. Correlated oscillations in glucose consumption, oxygen consumption, and intracellular free $\mathrm{Ca}(2+)$ in single islets of Langerhans. J Biol Chem. 275(9):6642-50.

38. Kennedy RT, Kauri LM, Dahlgren GM, 2000. Metabolic oscillations in beta-cells. Diabetes 51 Suppl 1:S152-61.

39. Li H, Chen Y, Jones AF, Sanger RH, Collis LP, Flannery R, McNay EC, Schwartzenbacher R, Bossy B, Bossy-Wetzel E, Bennett MVL, Pypaert M, Hickman JA, Smith PJS, Hardwick JM, Jonas EA. 2008. BCL-xL induces Drp1-dependent synapse formation in cultured hippocampal neurons. Proc Natl Acad Sci 105(6): 2169-2174.

40. Shum WW, Da Silva N, McKee M, Smith PJ, Brown D, Breton S. 2008. Transepithelial projections from basal cells are luminal sensors in pseudostratified epithelia. Cell. 135(6):1108-17.

41. Kang TM, Hilgemann DW. 2004. Multiple transport modes of the cardiac $\mathrm{Na}+/ \mathrm{Ca}+$ exchanger. Nature 427, 544-548.

42. Ammann D. 1986. Ion-selective microelectrodes Berlin: Springer-Verlag.

40 43. Pungor E. 1992. Working mechanism of ion-selective electrodes. Pure \& Appl. Chem. 64:503-507.

44. Huser M, Gehrig PH, Morf WE, Simon W, Lindner E, Jeney J, Toth K, Pungor E. 1991. Membrane Technology and Dynamic Response of Ion-Selective Liquid-Membrane Electrodes. Anal. Chem. 63:1380-1386.

45. Lindner E, Toth K, Pungor E, Morf WE, Simon W. 1978. Response time studies on neutral carrier ion-selective membrane electrodes. Anal. Chem. 50:1627-1631.

46. O'Malley D, Harvey J. 2007. MAPK-dependent actin cytoskeletal reorganization underlies BK channel activation by insulin. Eur. J. Neurosci. 25:673-682.

47. Terzic A, Kurachi Y. 1996. Actin microfilament disrupters enhance K(ATP) channel opening in patches from gui-nea-pig cardiomyocytes. J. Physiol 492 ( Pt 2):395-404.

50 48. Hamill OP, McBride DW. 1997. Induced membrane hypo/hyper-mechanosensitivity: a limitation of patch-clamp recording. Annu. Rev. Physiol 59:621-631.

49. Wang SQ, Song LS, Lakatta EG,Cheng H. 2001. $\mathrm{Ca}^{2+}$ signalling between single L-type $\mathrm{C}^{\mathrm{a} 2+}$ channels and ryanodine receptors in heart cells. Nature 410:592-596.

50. Strong JA, Fox AP, Tsien RW, Kaczmarek LK. 1987. Stimulation of protein kinase C recruits covert calcium channels in Aplysia bag cell neurons. Nature 325:714-717. 
51. Frankenhaeuser B, Hodgkin AL. 1956. The after-effects of impulses in the giant nerve fibres of Loligo. J Physiol. 131(2):341-76.

52. Adelman WJ, Fitzhugh R. 1975. Solutions of the Hodgkin-Huxley equations modified for potassium accumulation in a periaxonal space. Fed Proc. 1975 Apr;34(5):1322-9.

53. Hodgkin AL, Huxley AF. 1952. A quantitative description of membrane current and its application to conduction and excitation in nerve. J Physiol. 952 117(4):500-44.

54. Clay JR. 2005. Axonal excitability revisited. Prog Biophys Mol Biol. 88(1):59-90.

55. Orkand RK, Nicholls JG, Kuffler SW. 1966. Effect of nerve impulses on the membrane potential of glial cells in the central nervous system of amphibia. J Neurophysiol.29(4):788-806.

56. Kofuji P, Newman EA. 2004. Potassium buffering in the central nervous system.Neuroscience. 129(4):1045-56.

57. Rusakov DA, Fine A 2003. Extracellular $\mathrm{Ca}^{2+}$ depletion contributes to fast activity-dependent modulation of synaptic transmission in the brain. Neuron 37, 287-297.

58. Wilson GS, Johnson MA. 2008 In-vivo electrochemistry: what can we learn about living systems? Chem Rev. 108(7):2462-81.

59. Khan AS, Michael AC. 2003. Invasive consequences of using micro-electrodes and microdialysis probes in the brain. Trends in Anal Chem 22(9), 503-508.

60. Mitala CM, Wang Y, Borland LM, Jung M, Shand S, Watkins S, Weber SG, Michael AC. 2008. Impact of microdialysis probes on vasculature and dopamine in the rat striatum: a combined fluorescence and voltammetric study. J Neurosci Methods. 174(2):177-85.

61. Martin GR, Jain RK. 1994. Noninvasive measurement of interstitial pH profiles in normal and neoplastic tissue using fluorescence ratio imaging microscopy.Cancer Res. 54(21):5670-4.

62. Huang WC, Swietach P, Vaughan-Jones RD, Ansorge O, Glitsch MD. 2008. Extracellular acidification elicits spatially and temporally distinct Ca2+ signals. Curr Biol. 18(10):781-5.

63. Fais S, De Milito A, You H, Qin W. 2007. Targeting vacuolar H+-ATPases as a new strategy against cancer. Cancer Res. 67(22):10627-30.

64. Gatenby RA, Gawlinski ET, Gmitro AF, Kaylor B, Gillies RJ. 2006. Acid-mediated tumor invasion: a multidisciplinary study. Cancer Res. 66(10):5216-23.

65. Chesler M. 2003. Regulation and modulation of $\mathrm{pH}$ in the brain. Physiol. Rev. 1183-1221.

66. Fedirko N, Svichar N, Chesler M. 2006. Fabrication and use of high-speed, concentric h+- and $\mathrm{Ca}^{2+}$-selective microelectrodes suitable for in vitro extracellular recording. J. Neurophysiol. 96:919924.

67. Thomas RC. 2009. The plasma membrane calcium ATPase (PMCA) of neurones is electroneutral and ex-changes $2 \mathrm{H}^{+}$for each $\mathrm{Ca}^{2+}$ or $\mathrm{Ba}^{2+}$ ion extruded. J Physiol 587, 315-327.

68. Shah GN, Ulmasov B, Waheed A, Becker T, Makani S, Svichar N, Chesler M, Sly WS. 2005. Carbonic anhydrase IV and XIV knockout mice: roles of the respective carbonic anhydrases in buffering the EICS in brain. Proc Natl Acad Sci. 102(46):16771-6.

69. Hilvo M, Supuran CT, Parkkila S. 2007. Characterization and inhibition of the recently discovered carbonic anhydrase isoforms CA XIII, XIV and XV. Curr Top Med Chem. 7(9):893-9.

40 70. Fedirko N, Avshalumov M, Rice ME, Chesler M. 2007. Regulation of postsynaptic $\mathrm{Ca}^{2+}$ influx in hippocampal CA1 pyramidal neurons via extracellular carbonic anhydrase. J Neurosci. 27(5):1167-75.

71. Monshausen GB, Bibikova TN, Messerli MA, Shi C, Gilroy S. 2007. Oscillations in extracellular pH and reactive oxygen species modulate tip growth of Arabidopsis root hairs. Proc Natl Acad Sci 104 (52): 20996-21001.

72. Miesenbock G, De Angelis DA, Rothman JE. 1998. Visualizing secretion and synaptic transmission with $\mathrm{pH}$-sensitive green fluorescent proteins. Nature. Vol. 394, 192-5.

73. Pethig R, Jakubek LM, Sanger RH, Heart E, Corson ED, Smith PJS. 2005. Electrokinetic measurements of membrane capacitance and conductance for pancreatic beta-cells. IEE Proc Nanobiotechnol: 152(6): 189-93.

50 74. Pethig R, Menachery A, Heart E, Sanger RH, Smith PJS. 2008. Dielectrophoretic assembly of insulinoma cells and fluorescent nanosensors into three-dimensional 'pseudo-islet' constructs. IET Nanobiotechnology. 2(2): 31-38.

75. Stock C, Mueller M, Kraehling H, Mally S, Noël J, Eder C, Schwab A. 2007. pH nanoenvironment at the surface of single melanoma cells. Cell Physiol Biochem. 20(5):679-86.

76. Zhang X, Chen Y, Wang C, Huang LY. 2007. Neuronal somatic ATP release triggers neuronsatellite glial cell communication in dorsal root ganglia. Proc Natl Acad Sci U S A. 104(23):9864- 
77. Newman EA. 2003. Glial cell inhibition of neurons by release of ATP. J Neurosci. 23(5):1659-66.

78. Newman EA. 2004. A dialogue between glia and neurons in the retina: modulation of neuronal excitability. Neuron Glia Biol. 1(3):245-252.

79. Newman EA. 2006. A purinergic dialogue between glia and neurons in the retina. Novartis Found Symp. 276:193-202.

80. Lechner SG, Boehm S. 2004. Regulation of neuronal ion channels via P2Y receptors. Purinergic Signal 1(1): 31-41.

81. Deitmer JW, Brockhaus J, Casel D. 2006. Modulation of synaptic activity in Purkinje neurons by ATP. Cerebellum. 5(1):49-54.

82. Wang Z, Haydon PG, Yeung ES. 2000. Direct observation of calcium-independent intercellular ATP signal-ing in astrocytes. Anal Chem. 72(9):2001-7.

83. Beigi R, Kobatake E, Aizawa M, and Dubyak GR. 1999. Detection of local ATP release from activated platelets using cell surface-attached firefly luciferase. Am J Physiol. 276(Pt 1):C267-78.

84. Kim S, Lim YT, Soltesz EG, De Grand AM, Lee J, Nakayama A, Parker JA, Mihaljevic T, Laurence RG, Dor DM, Cohn LH, Bawendi MG, Frangioni JV. 2004. Near-infrared fluorescent type II quantum dots for sentinel lymph node mapping. Nat Biotechnol 22, 93-97.

85. Buck SM, Xu H, Brasuel M, Philbert MA, Kopelman R. 2004. Nanoscale probes encapsulated by biologically localized embedding (PEBBLEs) for ion sensing and imaging in live cells. Talanta. 63(1):41-59.

86. Kang TM, Markin VS, Hilgemann DW. 2003. Ion fluxes in giant excised cardiac membrane patches detected and quantified with ion-selective microelectrodes. J. Gen. Physiol. 121, 325-347.

87. Yamoah EN, Lumpkin EA, Dumont RA, Smith PJS, Hudspeth AJ, Gillespie PG. 1998. Plasma membrane $\mathrm{Ca}^{2+}$-ATPase extrudes $\mathrm{Ca}^{2+}$ from hair cell stereocilia. J. Neurosci. 18, 610-624

88. Molina A A, Verzi MP, Birnbaum AD, Yamoah EN, Hammar K, Smith PJS, Malchow RP. 2004. Neurotransmitter modulation of extracellular $\mathrm{H}+$ fluxes from isolated retinal horizontal cells of the skate. J. Physiol. 560, 639-657.

89. Devlin CL. 2001. 5-hydroxytryptamine stimulates net Ca2+ flux in the ventricular muscle of a mollusc (Busycon canaliculatum) during cardioexcitation. Biol. Bull. 200, 344-350.

90. Shirihai O, Smith P, Hammar K, Dagan D. 1998. Microglia generate external proton and potassium ion gradients utilizing a member of the H/K ATPase family. Glia 23, 339-348.

91. Breton S, Brown D. 2007. New insights into the regulation of V-ATPase dependent proton secretion. Am. J. Physiol. Renal Physiol. 292, F1-F10.

92. Boudko DY, Moroz LL, Linser PJ, Trimarchi JR, Smith PJS, Harvey WR. 2001a. In situ analysis of $\mathrm{pH}$ gradients in mosquito larvae using non-invasive, self-referencing, $\mathrm{pH}$-sensitive microelectrodes. J. Exp. Biol. 204, 691-699.

93. Pepperell JR, Kommineni K, Buradagunta S, Smith PJS, Keefe DL. 1999. Transmembrane regulation of intracellular calcium by a plasma membrane sodium/calcium exchanger in mouse ova. Biol. Reprod. 60, 1137-1143.

94. Boudko DY, Moroz LL, Harvey WR, Linser PJ. 2001b. Alkalinization by chloride/ bicarbonate pathway in larval mosquito midgut. Proc. Natl. Acad. Sci. U.S.A. 98, 15354-15359.

95. Trimarchi JR, Liu L, Smith PJS, Keefe DL. 2002. Apoptosis recruits two-pore domain potassium channels used for homeostatic volume regulation. Am. J. Physiol. Cell Physiol. 282, C588-C594.

96. Marcus DC, Shipley AM. 1994. Potassium secretion by vestibular dark cell epithelium demonstrated by vibrating probe. Biophys. J. 66, 1939-1942.

97. Doughty JM, Langton PD. 2001. Measurement of chloride flux associated with the myogenic response in rat cerebral arteries. J. Physiol. 534, 753-761.

98. Garber SS, Messerli MA, Hubert M, Lewis R, Hammar K, Indyk E, Smith PJS. 2005. Monitoring Clmovement in single cells exposed to hypotonic solution. J. Membrane Biol. 203, 101-110.

99. Land SC, Collett A. 2001. Detection of Cl- flux in the apical microenvironment of cultured foetal distal lung epithelial cells. J Exp Biol. 204(4):785-95.

100. Pelc R, Smith PJS, Ashley CC. 1996. In vivo recording of calcium fluxes accompanying 'catch' contraction of molluscan smooth muscle. J. Physiol. 497, 41P. 
Figure Legends

Figure 1: A diagrammatic representation of a section through the cell membrane depicting the heterogenous nature of the lipid and protein structures, a smeared charged layer depicted by the overlying colored clouds, as well as molecules in the boundary layer. The two molecular complexes in the section are the Vtype proton pump (left) and the sodium/potassium pump (right). Within the cytosol membrane proteins can be closely associated with actin fibers.

Figure 2: A diagrammatic representation of how a self-referencing ion selective (SERIS) electrode works. The illustration depicts a potentiometric microelectrode located at its two measurement poles in the EICS of a single cell and in close proximity to the plasma membrane. At both poles the sensor is placed within the chemical boundary layer, the diffusive layer established by ion transport, outside the plasma membrane and beyond the electrostatic layer limited by the Debye length. The near pole is number 1 and the far pole is numbered 2. The ground return is shown to the lower left. If two separate electrodes (E1 and E2) are used then drift is a characteristic of each sensor (upper right panel). A differential calculation of output generates $\mathrm{mV}$ variations, including values for drift, noise and background, being too large to extract the single cell signal. Moving one electrode between the two poles of translation (P1 and P2) results in the drift and background conditions being relatively common to both poles and subtracting out. The resulting differential is in the $\mu \mathrm{V}$ range and primarily comprises differences in the targeted analyte (lower right panel). With knowledge of background, distance of translation, the diffusion coefficient, and a calibration, this value can be converted to flux with Fick's $1^{\text {st }}$ equation (see text).

Figure 3: Left panel. An amperometric Whalen-style $\mathrm{O}_{2}$ electrode positioned next to a hippocampal neuron in culture. With mitochondria visualized by trimethylrhodamine ethyl ester (TMRE) fluorescence. Oxygen consumption and short term dynamic changes can be assessed at a single neuron level while observing through fluorescence imaging the action of glutamate toxicity on mitochondrial membrane potential. ${ }^{(36)}$

Middle and right panel A single fluorescent image of a hippocampal neuron tagged with a GFP-BCL ${ }_{x L}$ fusion protein (middle) using a lentivirus vector. An $\mathrm{O}_{2}$ electrode is subsequently positioned for measurement (right). In this image many neurons are present which do not express the molecule of interest. Expressing cells can thus be studied as individuals avoiding data being confused by non-expressing cells or heterogenous cell types in population studies. Expression $B C L_{x L}$ has been shown to increase the number of mitochondria in a neuron ${ }^{(39)}$ but reduce the overall level of oxygen consumption (L. Collis et al, in preparation).

Figure 4. Extracellular $\left[\mathrm{K}^{+}\right]$measurements near activated Slo channels overexpressed in a $\mathrm{CHO}$ cell. A fast response $\mathrm{K}^{+}$-selective microelectrode was repeatedly positioned at a position near the cell for 10 s and then at a position $20 \mu \mathrm{m}$ away for $10 \mathrm{~s}$. The cell was voltage clamped at 0 and $+60 \mathrm{mV}$. $\mathrm{K}^{+}$gradients from single channels (spikes) are captured when the electrode is in the near position. Insets show expansion of regions in A and B highlighted with bar. Single channel gradients are easily detected at lower depolarizing potentials when fewer channels are active. In B, single channel gradients sum together producing larger $\left[\mathrm{K}^{+}\right]$-dependent voltages. ${ }^{(34)}$

Figure 5. A schwannoma cell aggregate stably transfected with the pHlourin-GPI construct. The reporter is clearly expressed on the surface of the cells. Treatment with phospholipase $C$ results in the loss of label, confirming localization to the outer surface of the plasma membrane (P.J.S. Smith, S. Messerli and D. Graham, unpublished). 
Extracellular space

8

$\infty$

$\infty$ 
Two Separate Electrodes

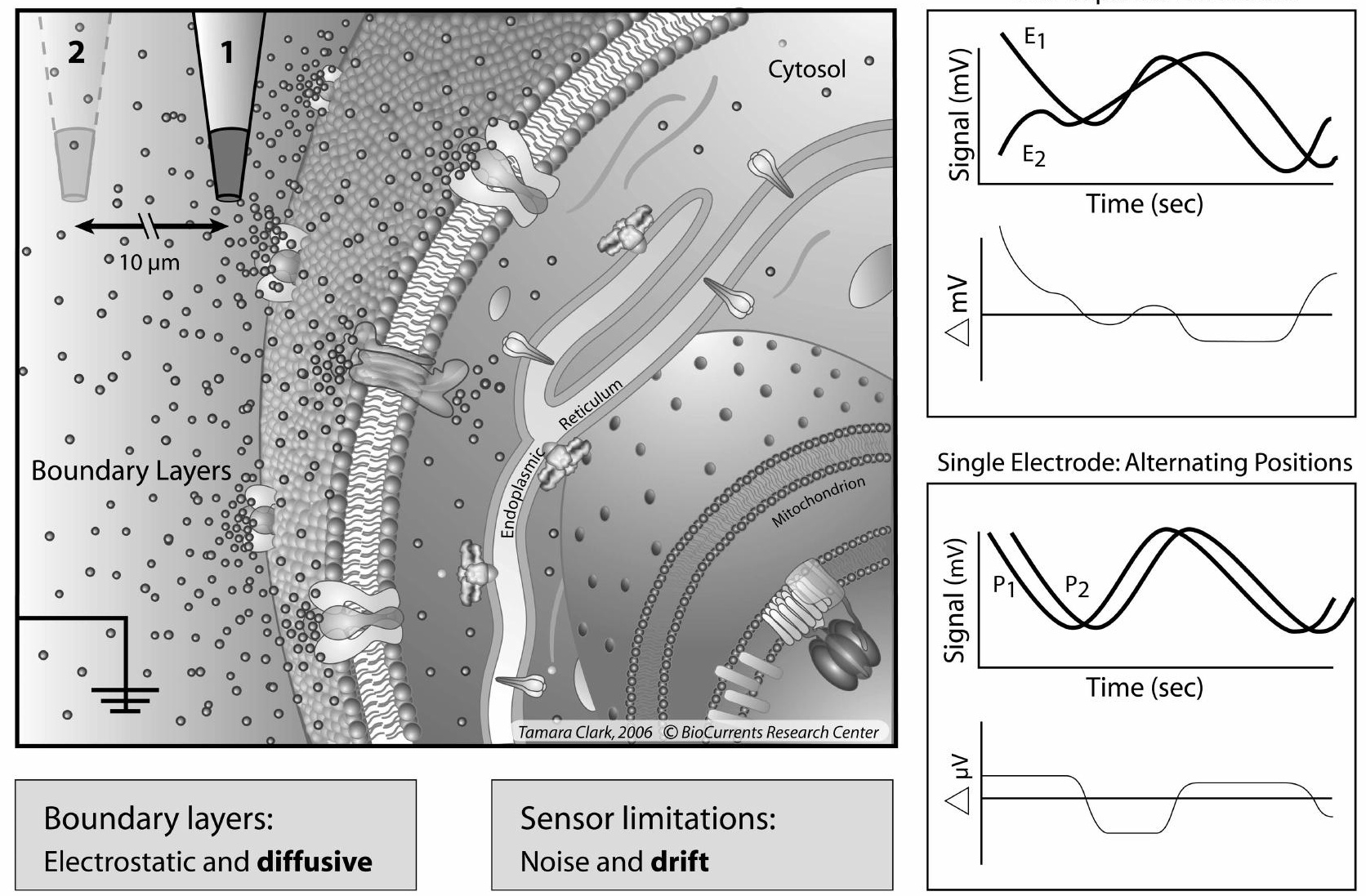




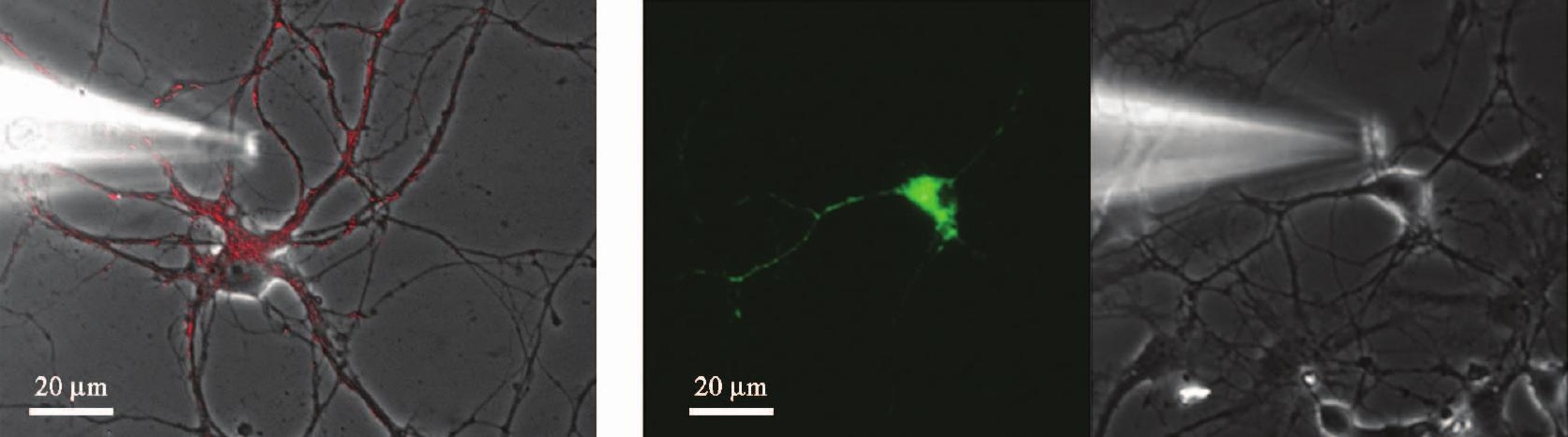



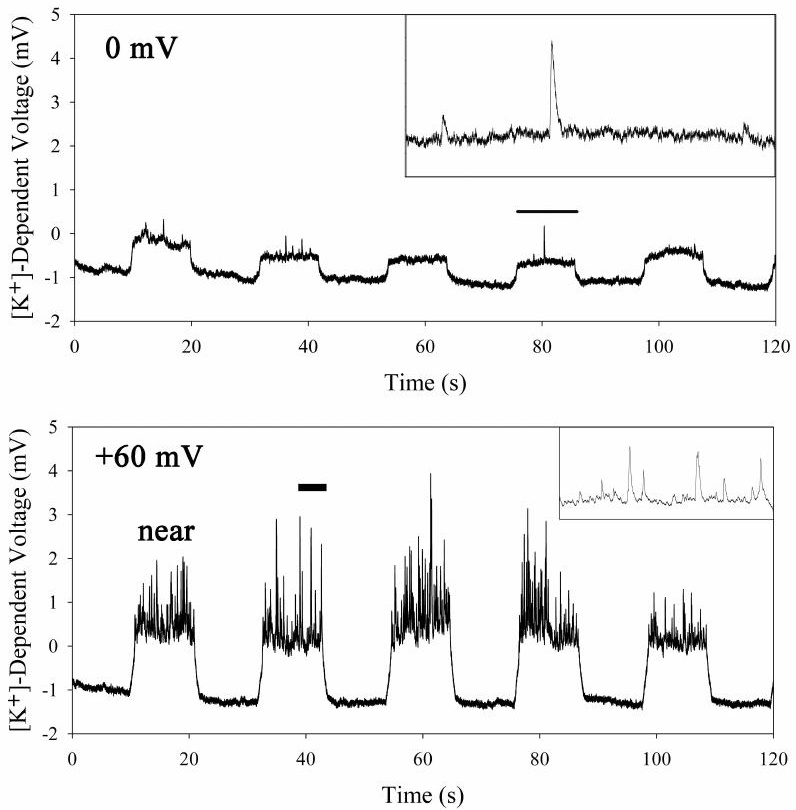
Table 1

\begin{tabular}{|c|c|}
\hline Ion Transporter & Source \\
\hline $\mathrm{Na}^{+} / \mathrm{K}^{+}$ATPase & cardiac myocytes $^{86}$ \\
\hline \multirow{3}{*}{$\mathrm{PM} \mathrm{Ca}^{2+}$-ATPase } & hair cells (hearing) \\
\hline & horizontal cells (vision) $^{88}$ \\
\hline & molluscan cardiac muscle ${ }^{89}$ \\
\hline $\mathrm{H}^{+} / \mathrm{K}^{+}$ATPase & Microglia $^{90}$ \\
\hline \multirow[t]{2}{*}{ V-ATPase } & $\begin{array}{lcl}\text { rat } & \text { vas } & \text { deferens } \\
\text { (reproduction) } & \end{array}$ \\
\hline & mosquito midgut $^{92}$ \\
\hline \multicolumn{2}{|l|}{ Ion Exchanger } \\
\hline \multirow[t]{2}{*}{$\mathrm{Na}^{+} / \mathrm{Ca}^{2+}$} & mouse ova $^{93}$ \\
\hline & cardiac myocytes $^{86}$ \\
\hline \multirow[t]{2}{*}{$\mathrm{Na}^{+} / \mathrm{H}^{+}$} & horizontal cells (vision) ${ }^{88}$ \\
\hline & cardiac myocytes $^{86}$ \\
\hline $\mathrm{Cl}^{-} / \mathrm{HCO}_{3}^{-}$ & mosquito midgut $^{94}$ \\
\hline \multicolumn{2}{|l|}{ Ion Channels } \\
\hline $\mathrm{Ca}^{2+}$-activated $\mathrm{K}^{+}(\mathrm{BK})$ & $\begin{array}{l}\begin{array}{l}\text { Xenopus } \\
\text { cells }^{33,34}\end{array} \text { oocytes, } \\
\end{array}$ \\
\hline Two-pore $\mathrm{K}^{+}$ & mouse zygote ${ }^{95}$ \\
\hline Voltage-dependent $\mathrm{K}^{+}$ & strial marginal cells ${ }^{96}$ \\
\hline Voltage-gated $\mathrm{K}^{+}$ & cardiac myocytes $^{86}$ \\
\hline \multirow[t]{2}{*}{$\mathrm{Cl}^{-}$} & cerebral arteries $^{9 /}$ \\
\hline & $\begin{array}{l}\text { human embryonic kidney }{ }^{98} \\
\text { lung epithelia }\end{array}$ \\
\hline Voltage-gated $\mathrm{Ca}^{2+}$ & molluscan smooth muscle ${ }^{100}$ \\
\hline \multicolumn{2}{|c|}{$\begin{array}{l}\text { Table 1. A list of ion transporters, exchangers and } \\
\text { channels that have been characterized with self- } \\
\text { referencing of ion-selective microelectrodes in native } \\
\text { cells, tissues and heterologous expression systems. In } \\
\text { most cases the transport protein was known to exist } \\
\text { using other methods or was identified with specific } \\
\text { pharmacological inhibitors. }\end{array}$} \\
\hline
\end{tabular}

